\title{
Research on Effect of Heap Loading on Deformation and Mechanical Properties of Bridge Double Pile Foundation on Steep Slope
}

\author{
Hao Luo \\ Shanghai Maritime University, Shanghai, China \\ Email: 527338857@qq.com
}

How to cite this paper: Luo, H. (2020) Research on Effect of Heap Loading on Deformation and Mechanical Properties of Bridge Double Pile Foundation on Steep Slope. Open Journal of Civil Engineering, $10,117-130$.

https://doi.org/10.4236/ojce.2020.102011

Received: April 7, 2020

Accepted: April 27, 2020

Published: April 30, 2020

Copyright $\odot 2020$ by author(s) and Scientific Research Publishing Inc. This work is licensed under the Creative Commons Attribution International License (CC BY 4.0).

http://creativecommons.org/licenses/by/4.0/

\begin{abstract}
In order to analyze the deformation and stress characteristics of the pile foundation on the slope, this paper uses the finite element software Abaqus for numerical simulation. The displacement and stress data of pile under different working conditions (the combination of heap load and vertical load and horizontal load and inclined load) were collected; the distribution of pile displacement, axial force and bending moment were analyzed. Simulation results show that: slope top loading has little effect on vertical displacement; when the heap load exceeds $200 \mathrm{kPa}$, the horizontal displacement is greatly affected. Pile axial force decreases with pile burial depth; pile lateral resistance plays a more adequate role in the rock and soil layer. The bending moment of double pile foundation is positive at the top and negative at the bottom. Applied oblique load has obvious $\mathrm{p}-\Delta$ effect.
\end{abstract}

\section{Keywords}

High and Steep Slope, Double Pile Foundation, Numerical Modeling, Heap Load, Abaqus, Influence Degree

\section{Introduction}

With the rapid development of our country's economy, roads and railways are extended to all parts of the country; in some mountainous and hilly areas, many bridge piles need to be located on steep slopes due to the terrain. Compared with the pile foundation on the flat ground, the pile foundation on the steep slope has certain particularity. In addition to bearing the load of the superstructure, it usually also bears the soil pressure from the slope. Therefore, it is of practical significance to study the deformation and stress of double pile foundation on the 
slope. Many experts and scholars at home and abroad have carried out in-depth research on the impact of vertical and horizontal loads on pile foundation. Zhao Minghua [1] adopted the finite element method to simulate the field tilting load test and the field negative friction test, and analyzed the stress characteristics of foundation pile under the combined action of tilting load and negative friction. Feng Zhongju [2] established a three-dimensional spatial model of bridge pile foundation in deep soft foundation area by theoretical analysis and numerical simulation, and analyzed the variation rules of vertical ultimate bearing capacity, pile tip resistance and pile lateral resistance of pile foundation under different working conditions. Zheng Gang [3] established a numerical model by using the limit analysis method of discontinuous layout optimization (DLO) to analyze the influence of slope geometry size, soil parameters and foundation position on the ultimate bearing capacity of slope strip foundation and slope failure mode. Chu Chengfu [4] adopted the " $m$ " method to simulate pile-soil interaction, established the pile foundation control differential equation according to the force and torque balance conditions, established the second-order precision difference equation, and numerically simulated the displacement and internal force of the foundation pile. Luo Weihua [5] used finite element software Marc to analyze the influence of pile spacing change, pile stiffness change, rock-socketed depth change and rock-soil quality around pile on the stress and displacement of double-row piles of pile pier. Zhao Minghua [6] established an improved finite rod element method applied to the analysis of internal force displacement of pile foundation of bridge with high and steep slopes through the treatment of pile load and boundary conditions.

In summary, at present, there are many researches on the bearing characteristics of single pile, and most of them are on the pile foundation on the flat ground, and there are few researches on the deformation and stress of double pile foundation under steep slope. The numerical simulation method is used to study the deformation and stress characteristics of double pile foundation under the action of pile load and various loads on the high and steep slope.

\section{Finite Element Model}

Abaqus is a powerful set of numerical software for engineering simulation. In this paper, the general finite element software Abaqus is used for numerical simulation analysis. Abaqus is very effective in dealing with the problems of soil material nonlinearity and complex contact between pile and soil, and it is an effective tool for analyzing the problems of pile-soil interaction.

The pile body adopts the linear elastic body constitutive model, the soil body adopts the Mohr-Coulomb constitutive model, the pile-soil contact adopts the contact pair to realize, the model is a three-dimensional solid model, the soil body diameter is 20 times the pile body diameter, and the pile bottom soil depth is 20 times the diameter of the pile. Since the pile-soil model is completely symmetrical, in order to facilitate calculation, half of the model is used for calcula- 
tion. See Table 1 for the selection results of soil physical and mechanical parameters.

In the calculation process, the left and right sides of the model use fixed boundaries in the $\mathrm{x}$ direction, the back side of the model uses fixed boundaries in the $y$ direction, the bottom of the model uses fixed boundaries in the $\mathrm{x}, \mathrm{y}$, and $\mathrm{z}$ directions. The other surfaces all use free boundaries, and the mesh of the model is shown in Figure 1.

\section{Model Validation}

In order to verify the accuracy of the model and the rationality of parameter selection, the example in literature [7] is used for model verification. Literature [7] described a field test study on a highway in Hunan Province. Based on the measured results, this paper uses Abaqus to simulate the field test. The comparison between the calculation results and the test results is shown in Figure 2.

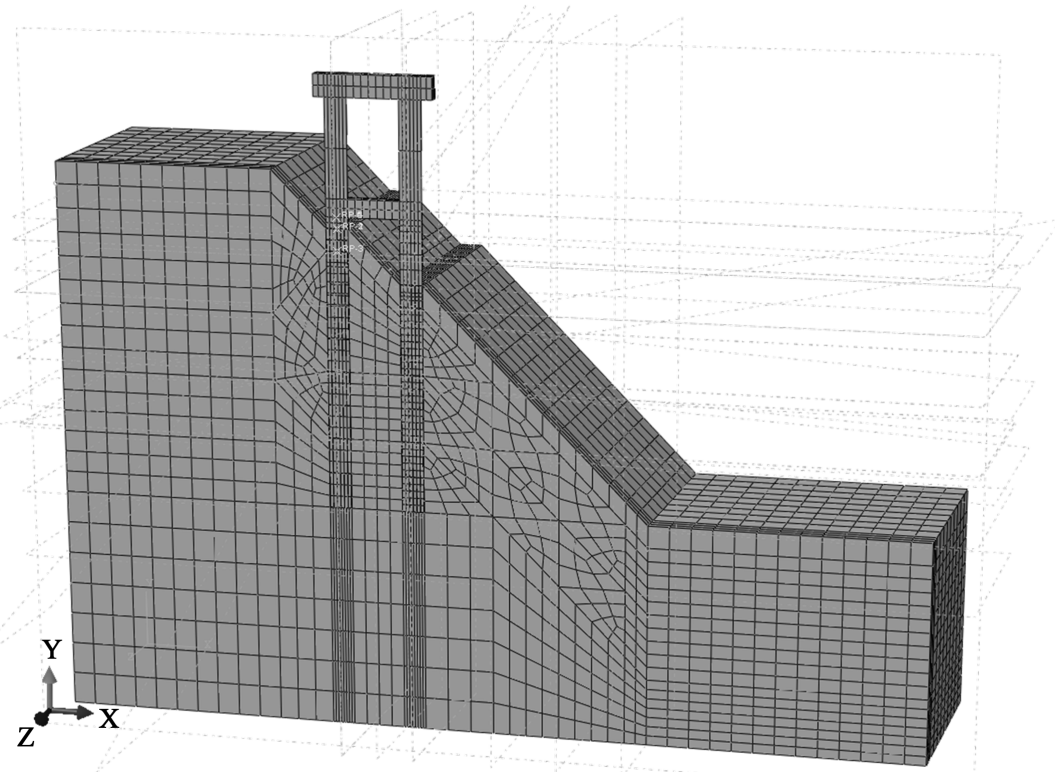

Figure 1. Three-dimensional finite element meshing of pile foundation of rock slope bridge.

Table 1. Physical and mechanical parameters of rock and soil layers.

\begin{tabular}{cccccc}
\hline Soil name & $\begin{array}{c}\text { Natural } \\
\text { density } \\
\left(\mathrm{g} \cdot \mathrm{cm}^{-3}\right)\end{array}$ & $\begin{array}{c}\text { Characteristic } \\
\text { value of bearing } \\
\text { capacity }(\mathrm{kPa})\end{array}$ & $\begin{array}{c}\text { Elastic } \\
\text { Modulus } \\
(\mathrm{MPa})\end{array}$ & $\begin{array}{c}\text { Cohesion } \\
(\mathrm{kPa})\end{array}$ & $\begin{array}{c}\text { Internal } \\
\text { friction } \\
\text { angle }\left(^{\circ}\right)\end{array}$ \\
\hline Planting soil & 1.90 & 160 & 150 & 25 & 18 \\
Gravel silty clay & 1.95 & 180 & 250 & 25 & 20 \\
$\begin{array}{c}\text { Strongly weathered } \\
\text { dolomite limestone }\end{array}$ & 2.15 & 380 & 3600 & 40 & 25 \\
$\begin{array}{c}\text { Moderately weathered } \\
\text { dolomite limestone }\end{array}$ & 2.30 & 1200 & 7800 & 60 & 40 \\
\hline
\end{tabular}




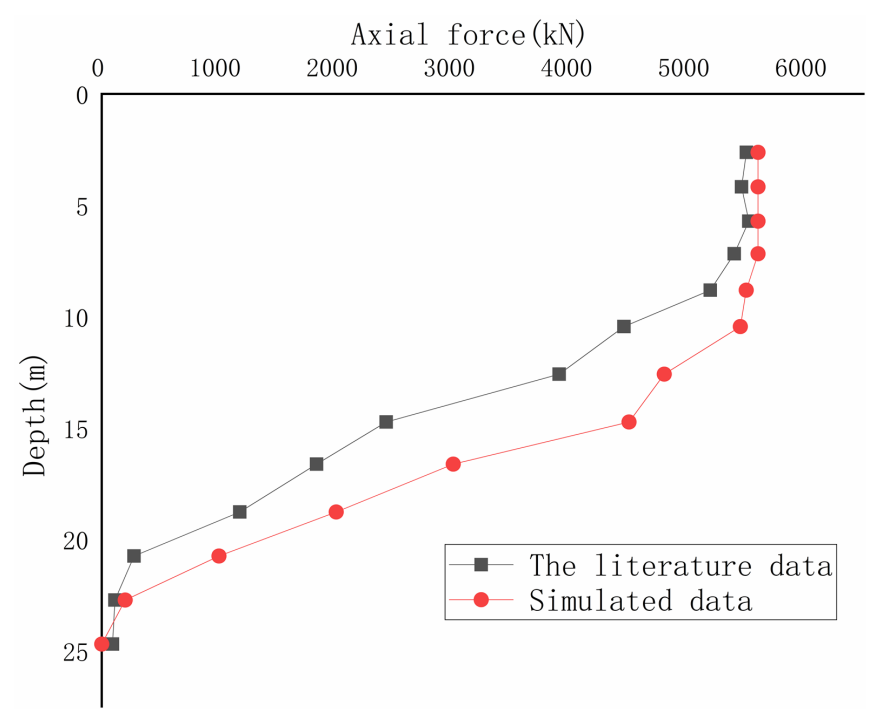

Figure 2. Comparison of calculation results with literature measurement results.

From the figure, it can be seen that the results calculated by the finite element software are in good agreement with the field test results, indicating the meta-results can reflect the true characteristics of the pile.

\section{Model Introduction and Calculation Conditions}

\subsection{Model Introduction}

This article selects the examples in literature [7] for further analysis. The diameter of the double pile is $2 \mathrm{~m}$, the length of the pile is $25 \mathrm{~m}$, and the height of the pier is $8.88 \mathrm{~m}$. The elastic modulus of the pile, column and beam is $2.95 \times 105$ $\mathrm{MPa}$. The distribution of soil around the pile and the size of the pile foundation are shown in Figure 3.

\subsection{Calculation Condition}

In order to better simulate the effect of stacking on the deformation and stress of the double-pile foundation, I used three combined loading conditions: stacking and vertical loads, stacking and horizontal loads, and stacking and tilting loads. Under the first working condition, assuming that the horizontal load $\mathrm{H}=0$, under the action of different heap loads $\mathrm{N}(200 \mathrm{kPa}, 225 \mathrm{kPa}, 250 \mathrm{kPa}, 275 \mathrm{kPa}, 300$ $\mathrm{kPa}, 325 \mathrm{kPa})$, applied load vertical V (8 MPa, $16 \mathrm{MPa}, 24 \mathrm{MPa}, 32 \mathrm{MPa}, 40$ $\mathrm{MPa}, 48 \mathrm{MPa}$ ) in stages. Under the second working condition, assuming the vertical load $\mathrm{V}=0$, under the action of different stacking loads $\mathrm{N}(200 \mathrm{kPa}, 225 \mathrm{kPa}$, $250 \mathrm{kPa}, 275 \mathrm{kPa}, 300 \mathrm{kPa}, 325 \mathrm{kPa}$ ), applied the horizontal load H (500 kPa, 600 $\mathrm{kPa}, 700 \mathrm{kPa}, 800 \mathrm{kPa}, 900 \mathrm{kPa}, 1000 \mathrm{kPa}$ ) in stages, Under the third working condition, under the effect of different stacking N $(200 \mathrm{kPa}, 225 \mathrm{kPa}, 250 \mathrm{kPa}$, $275 \mathrm{kPa}, 300 \mathrm{kPa}, 325 \mathrm{kPa})$, vertical load V (8 MPa, $16 \mathrm{MPa}, 24 \mathrm{MPa}, 32 \mathrm{MPa}, 40$ $\mathrm{MPa}, 48 \mathrm{MPa}$ ) and horizontal load H (500 kPa, $600 \mathrm{kPa}, 700 \mathrm{kPa}, 800 \mathrm{kPa}, 900$ $\mathrm{kPa}, 1000 \mathrm{kPa}$ ) were applied at the same level. 


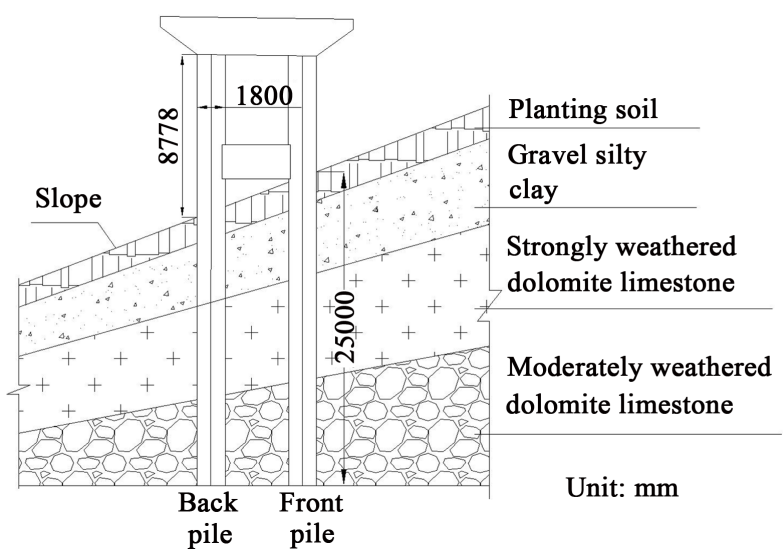

Figure 3. Size of pile foundation and distribution of rock and soil layers.

\section{Calculation Result Analysis}

\subsection{Combination of Stacking and Vertical Loads}

Assuming that there is no horizontal load $(\mathrm{H}=0)$, under the action of different stacking N (200 kPa, $225 \mathrm{kPa}, 250 \mathrm{kPa}, 275 \mathrm{kPa}, 300 \mathrm{kPa}, 325 \mathrm{kPa})$, graded vertical load V (8 MPa, $16 \mathrm{MPa}, 24 \mathrm{MPa}, 32 \mathrm{MPa}, 40 \mathrm{MPa}, 48 \mathrm{MPa}$ ), to simulate the impact of pile loading on high steep slopes on the vertical bearing capacity of the project pile foundation.

The drawing of the load-displacement curve of the pile under various loads and the axial force curve of the pile body is shown in Figure 4 .

As can be seen in Figure 4, as the vertical load increases, both the vertical and horizontal displacements of the pile top increase, and the vertical and horizontal displacement of the front pile are slightly smaller than the rear pile. In addition, with the increase in the slope top load, the vertical displacement of the pile top changes little, while the horizontal displacement changes greatly. Table 2 and Table 3 give the vertical and horizontal displacement of the pile top under different loading effects and the degree of influence of the stacking load on the vertical and horizontal displacement changes. It can be seen from the table that under different stacking loads, the effect of vertical displacement is very small, the largest is only 3.5\%, which can be ignored, and the degree of influence of horizontal displacement is very large, the maximum can reach $1271.6 \%$. For example, when the vertical load is $24 \mathrm{MPa}$ and the stacking load is $300 \mathrm{kPa}$, the influence degree of the vertical displacement generated by the slope top is $-0.2 \%$, and the influence degree of the horizontal displacement is $414.7 \%$.

When the vertical load is $16 \mathrm{MPa}$, the displacement curves of different pile tops are shown in Figure 5.

It can be seen from Figure 5(a) that with the increase of the stacking load, the vertical displacement of the rear pile will be slightly larger than that of the front pile, and the change rule of the vertical displacement of the front and rear double piles is basically similar. When the stacking load is about $200 \mathrm{kPa}$, an extreme point appears in the vertical displacement, that is, there is an optimal 


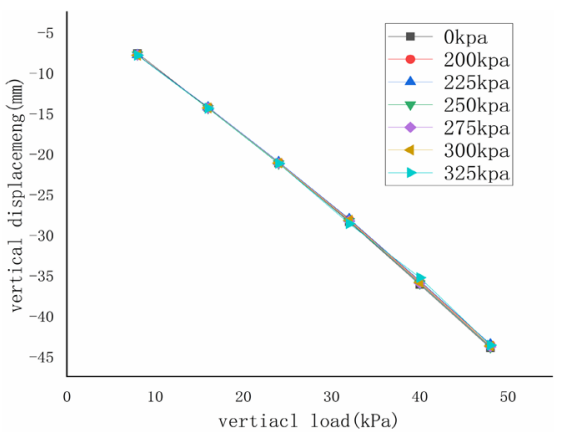

(a)

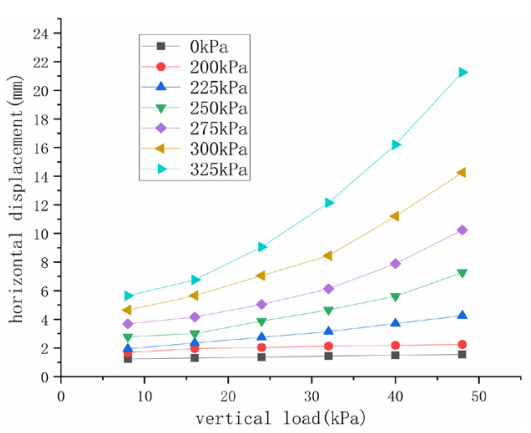

(b)

Figure 4. Load-displacement curve under different heap loads. (a) Vertical displacement; (b) Horizontal displacement.

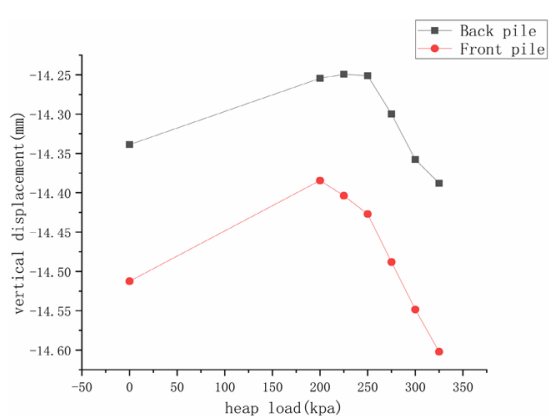

(a)

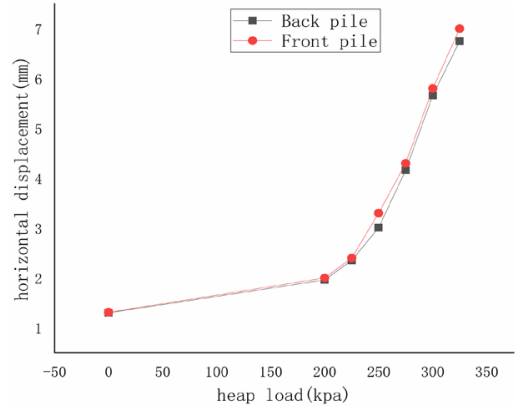

(b)

Figure 5. When the vertical load is $16 \mathrm{MPa}$, the top displacement of different piles. (a) Vertical displacement; (b) Horizontal displacement.

Table 2. Statistics of vertical displacement of pile top under different stacking.

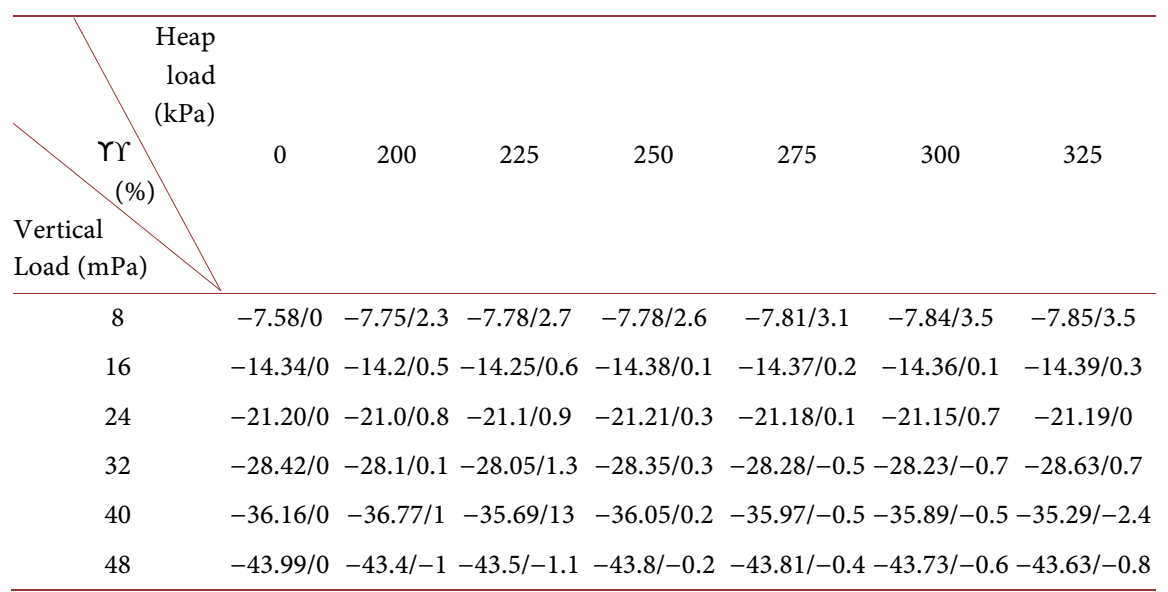

Note: Where $\Upsilon=\frac{D_{N}-D_{0}}{D_{0}}, \Upsilon$ is the degree of influence of pile loading on the displacement of the pile top. $D_{N}$ is the pile top displacement when the load is $N, D_{0}$ is the pile top displacement when the load is 0 .

stacking value to minimize the vertical displacement of the pile top, however, the loading has little effect on the vertical displacement, which is only $10 \mathrm{~mm}$ smaller than the maximum vertical displacement, which can be ignored. As shown in 
Table 3. Statistics of horizontal displacement of pile top under different stacking.

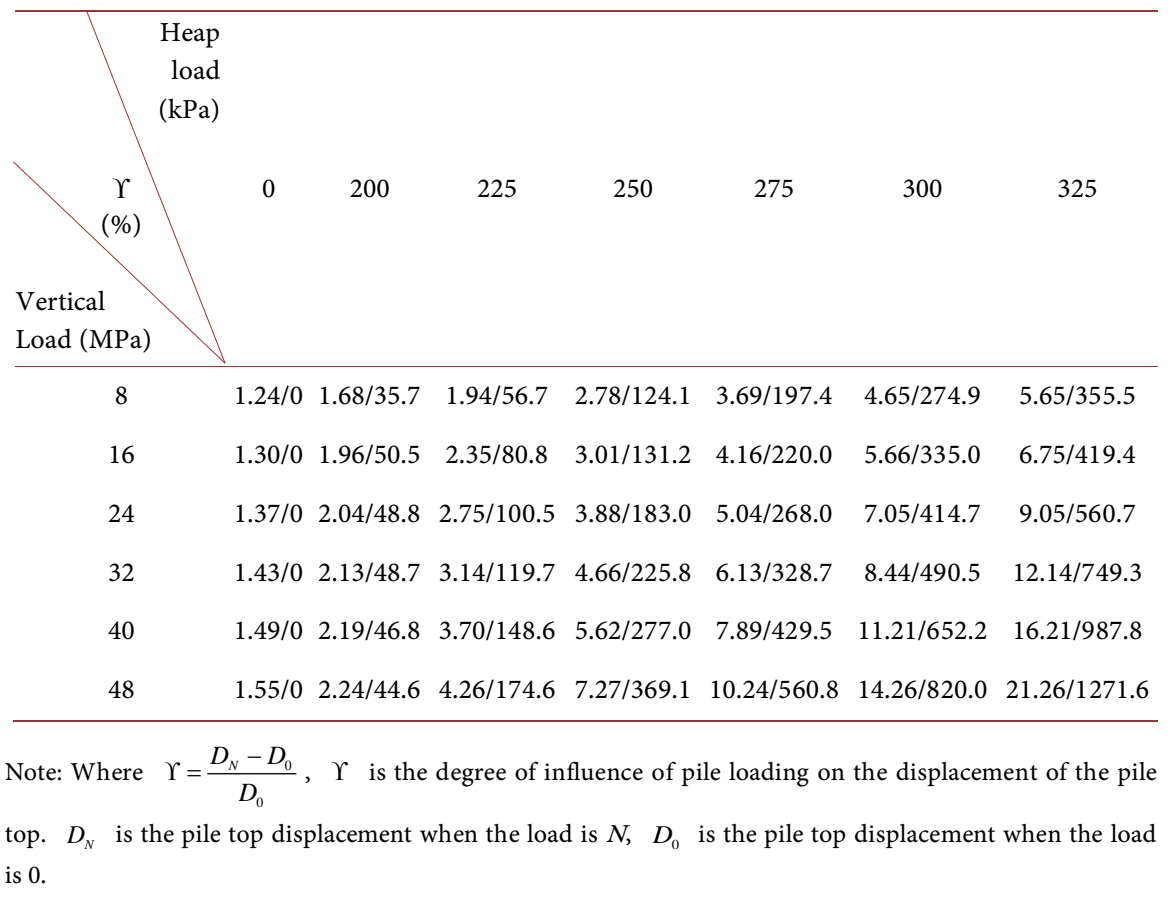

Figure 5(b), as the stacking load increases, the horizontal displacement of the rear pile will also be slightly larger than that of the front pile. When the stacking load is less than $200 \mathrm{kPa}$, the development of horizontal displacement is very slow, and the horizontal displacement of the pile top is within $0.5 \mathrm{~mm}$. When the stacking load reaches $200 \mathrm{kPa}$, the horizontal displacement develops rapidly, reaching $7 \mathrm{~mm}$. This shows that there is a critical stacking value. When the stacking load is greater than this value, the horizontal displacement will increase faster, and it is easy to exceed the limit horizontal displacement value. The reason for this stacking threshold is that when the top of the slope is small, the stress propagation does not reach the vicinity of the pile, nor does it have a thrust effect on the pile. In actual engineering, it should be avoided as much as possible.

Under different stacking loads, the axial force of the pile body is shown in Figure 6.

It can be seen from Figure 6 that the axial force of the pile body gradually decreases with the depth of the pile, indicating that the measured resistance of the pile bears part of the load from the upper part. When the pile depth is more than $13 \mathrm{~m}$, the axial force of the pile body does not change much. When the pile depth is less than $13 \mathrm{~m}$, the axial force of the pile body begins to decrease rapidly. This is because the pile depth of $13 \mathrm{~m}$ happens to be the boundary between clay and limestone, and limestone can better exert the resistance of the pile.

\subsection{Combination of stacking and Horizontal Loads}

Assuming no effect of vertical load $(\mathrm{V}=0)$, under the action of different 


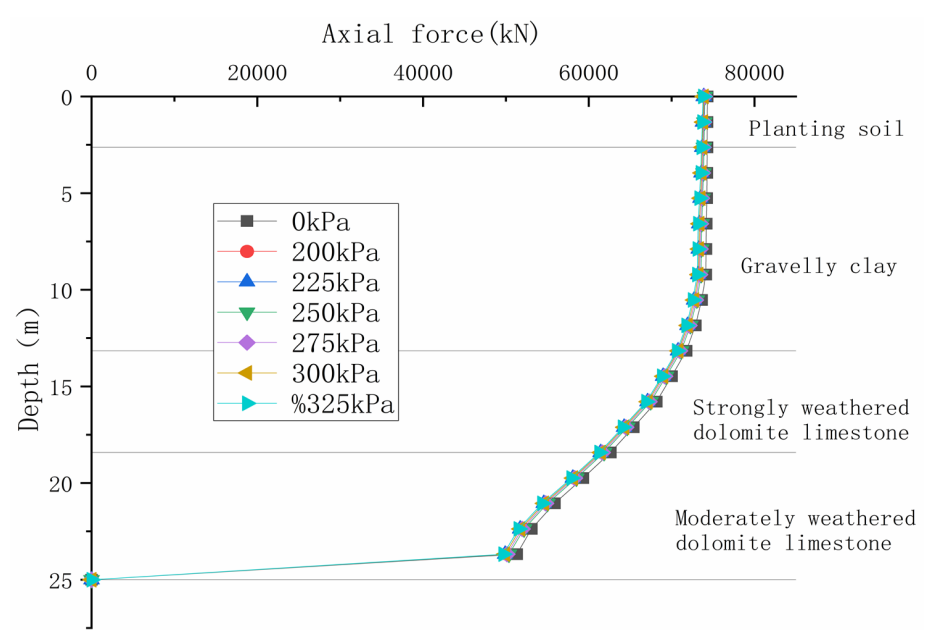

Figure 6. Axial force distribution curve of pile body.

stacking N (200 kPa, $225 \mathrm{kPa}, 250 \mathrm{kPa}, 275 \mathrm{kPa}, 300 \mathrm{kPa}, 325 \mathrm{kPa})$, the horizontal load H (500 kPa, $600 \mathrm{kPa}, 700 \mathrm{kPa}, 800 \mathrm{kPa}, 900 \mathrm{kPa}, 1000 \mathrm{kPa})$ is loaded stepwise to simulate the top of the high steep slope effect of stacking on horizontal bearing capacity of engineering pile foundation.

The load displacement curve of the pile under various loads is shown in Figure 7.

It can be seen from Figure 7 that the horizontal displacement of the pile top increases with the increase of the horizontal load, and increases with the increase of the slope top load. Table 4 gives the horizontal displacement of the pile top under different loading effects and the degree of influence of the loading on the horizontal displacement changes. It can be seen that the degree of influence of the heap load on the horizontal displacement increases as the heap load increases. Under the horizontal load of $600 \mathrm{kPa}$, the influence degree is only $6.2 \%$ when the heap load is $225 \mathrm{kPa}$, and the influence degree is $113.6 \%$ when the heap load is $325 \mathrm{kPa}$.

When drawing a horizontal load of $700 \mathrm{kPa}$, the horizontal displacement curve of the pile top under different stacking loads is shown in Figure 8.

It can be seen from Figure 8 that there is a critical value. When the slope top load is less than $200 \mathrm{kPa}$, the horizontal displacement of the pile top grows very slowly, and the horizontal displacement increases only $0.2 \mathrm{~mm}$. When the stacking load is $300 \mathrm{kPa}$, the horizontal displacement increases by $6.98 \mathrm{~mm}$. Therefore, in actual engineering, the top load of the slope should be avoided as much as possible.

Under different loadings, the section bending moment of the pile is shown in Figure 9.

It can be seen from Figure 9 that the bending moment will increase with the increase of the load, the maximum bending moment point is at the top of the pile, the zero bending moment point is located at the pile body $5-10 \mathrm{~m}$, and the position of the zero bending moment point is toward the pile move down. 


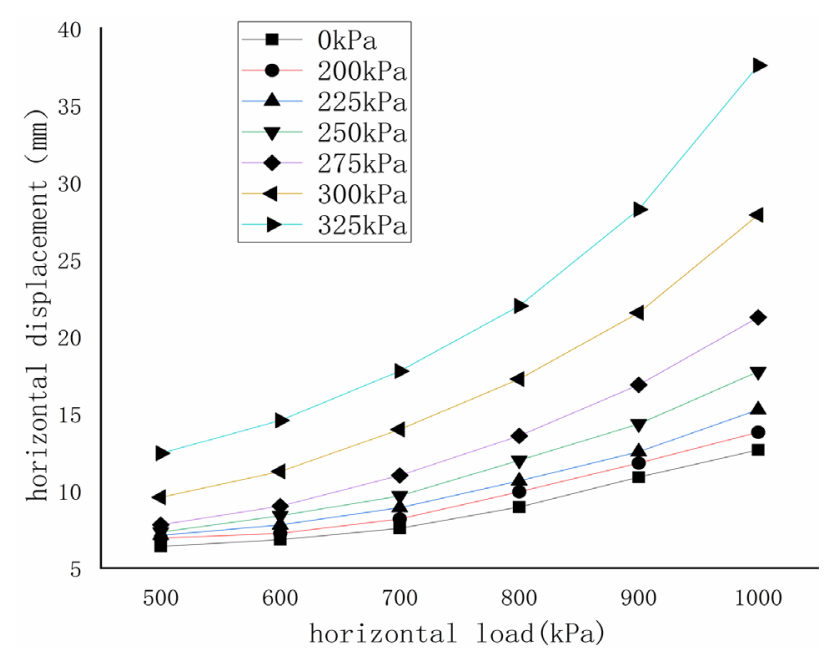

Figure 7. Pile top load-horizontal displacement curve under different stacking loads.

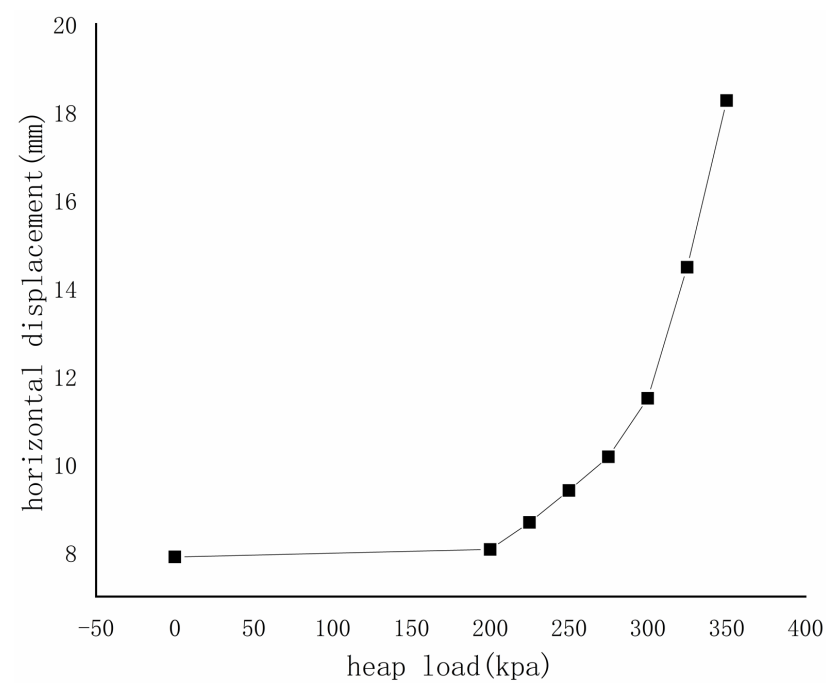

Figure 8. The horizontal displacement of the pile top under different stacking loads.

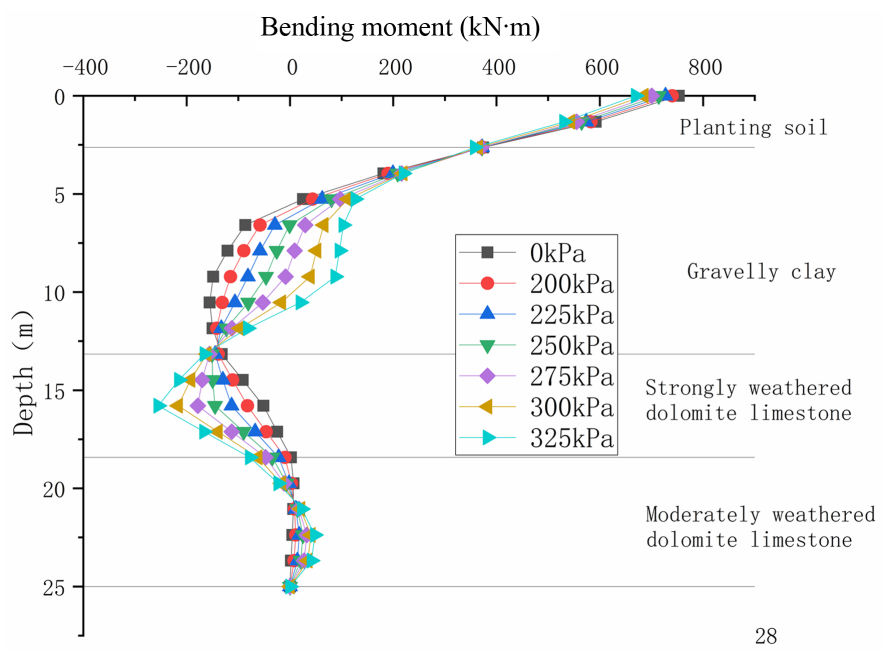

Figure 9. Pile bending moment. 
Table 4. Statistics of vertical displacement of pile top under different stacking.

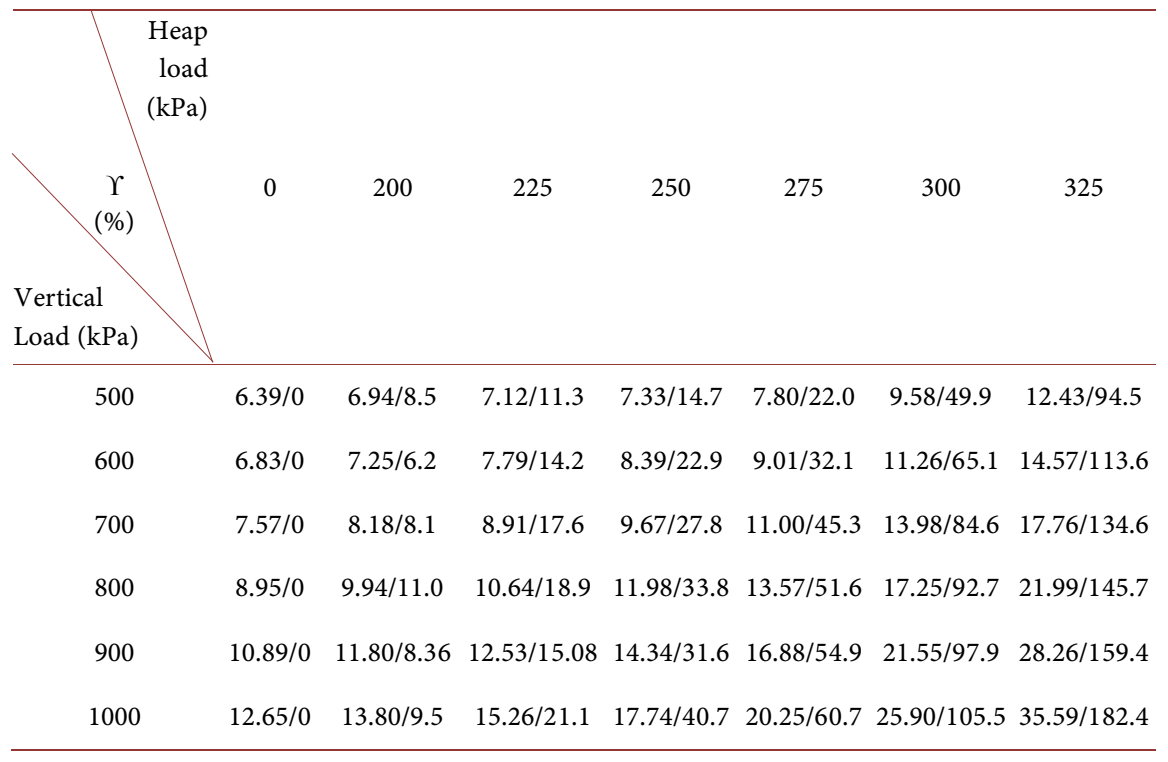

Note: Where $\Upsilon=\frac{D_{N}-D_{0}}{D_{0}}, \Upsilon$ is the degree of influence of pile loading on the displacement of the pile top. $D_{N}$ is the pile top displacement when the load is $N, D_{0}$ is the pile top displacement when the load is 0 .

Different from the single pile, the upper bending moment of the double pile structure is positive, and the lower bending moment is negative. The reason for the difference from the single pile is that the double pile structure is integrated with the tie beam and the cover beam, which can share the load. At a depth of about $13 \mathrm{~m}$, there is a point where each stacking curve passes through. The depth of this point is just at the boundary between the upper and lower soil layers.

\subsection{Combination of Stacking and Inclined Loads}

Under different loads N (200 kPa, $225 \mathrm{kPa}, 250 \mathrm{kPa}, 275 \mathrm{kPa}, 300 \mathrm{kPa}, 325 \mathrm{kPa})$, the vertical load V (8 MPa, $16 \mathrm{MPa}, 24 \mathrm{MPa}, 32 \mathrm{MPa}, 40 \mathrm{MPa}, 48 \mathrm{MPa}$ ) and horizontal load $\mathrm{H}$ (500 kPa, $600 \mathrm{kPa}, 700 \mathrm{kPa}, 800 \mathrm{kPa}, 900 \mathrm{kPa}, 1000 \mathrm{kPa}$ ) loading at the same level, to simulate the impact of pile top load on the bearing capacity of pile foundation under complex load conditions in high and steep slopes. The stress field at the last stage of combined load is shown in Figure 10.

The load-displacement curve of piles under various levels of loading is shown in Figure 11.

As can be seen from Figure 11 and Table 5 and Table 6, the influence of horizontal load and load on vertical displacement is very small, the maximum influence degree is only $5.6 \%$, the impact is negligible. However, compared with the conditions with only heap load and horizontal load, the horizontal displacement under inclined load is greater than that under only horizontal load under the same horizontal load. When the load horizontal component is $700 \mathrm{kPa}$ and 

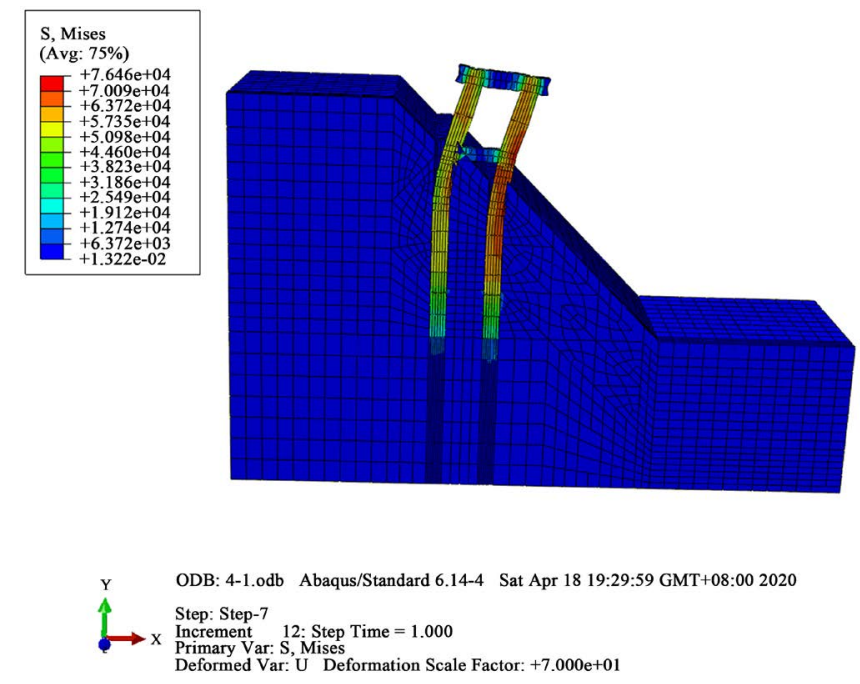

Figure 10. Stress cloud of the last stage of combined load.

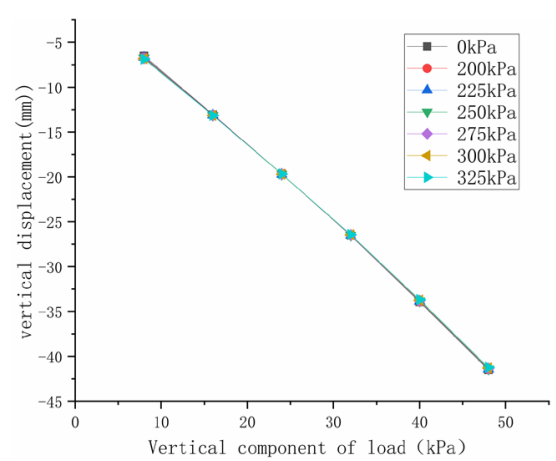

(a)

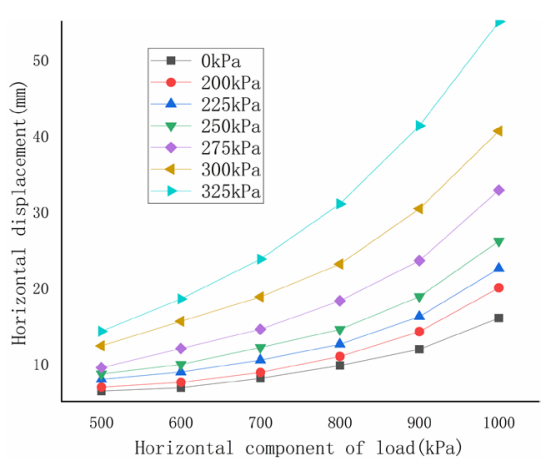

(b)

Figure 11. Load-displacement curve of pile top under different stacking loads. (a) Vertical displacement; (b) Horizontal displacement.

Table 5. Statistics of vertical displacement of pile top under different stacking.

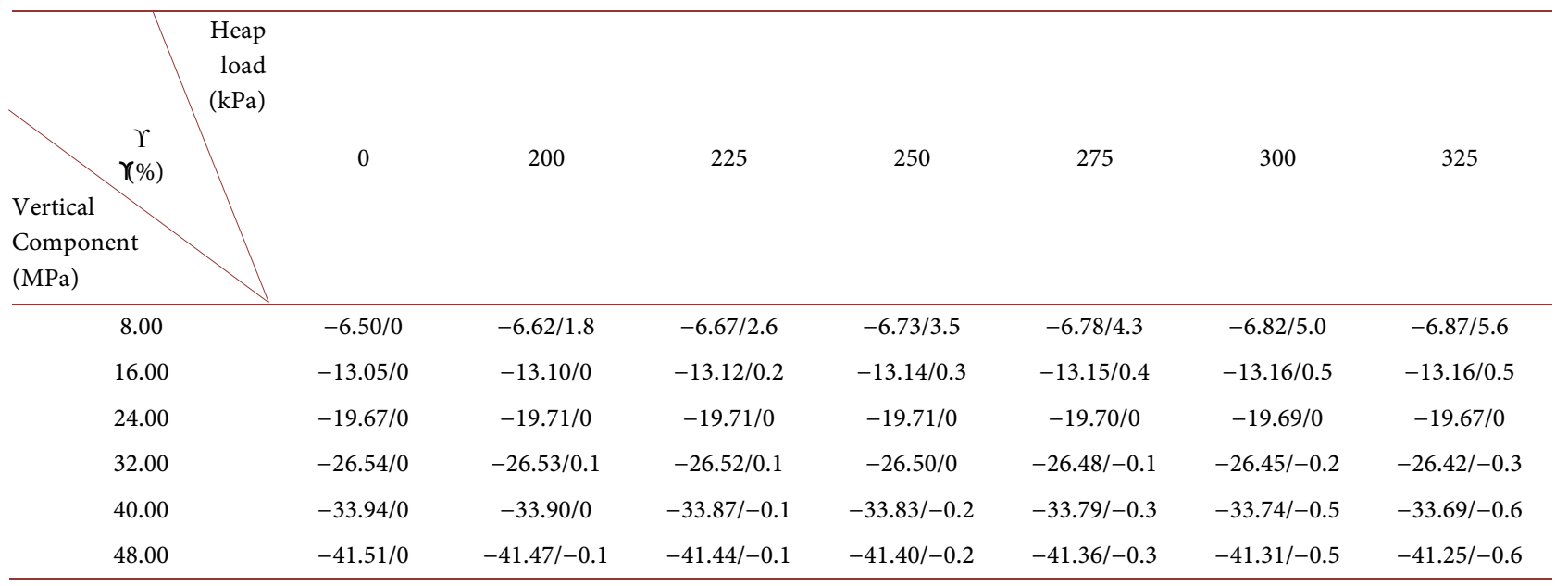

Note: Where $\Upsilon=\frac{D_{N}-D_{0}}{D_{0}}, \Upsilon$ is the degree of influence of pile loading on the displacement of the pile top. $D_{N}$ is the pile top displacement when the load is $N, D_{0}$ is the pile top displacement when the load is 0 . 
Table 6. Statistics of vertical displacement of pile top under different stacking.

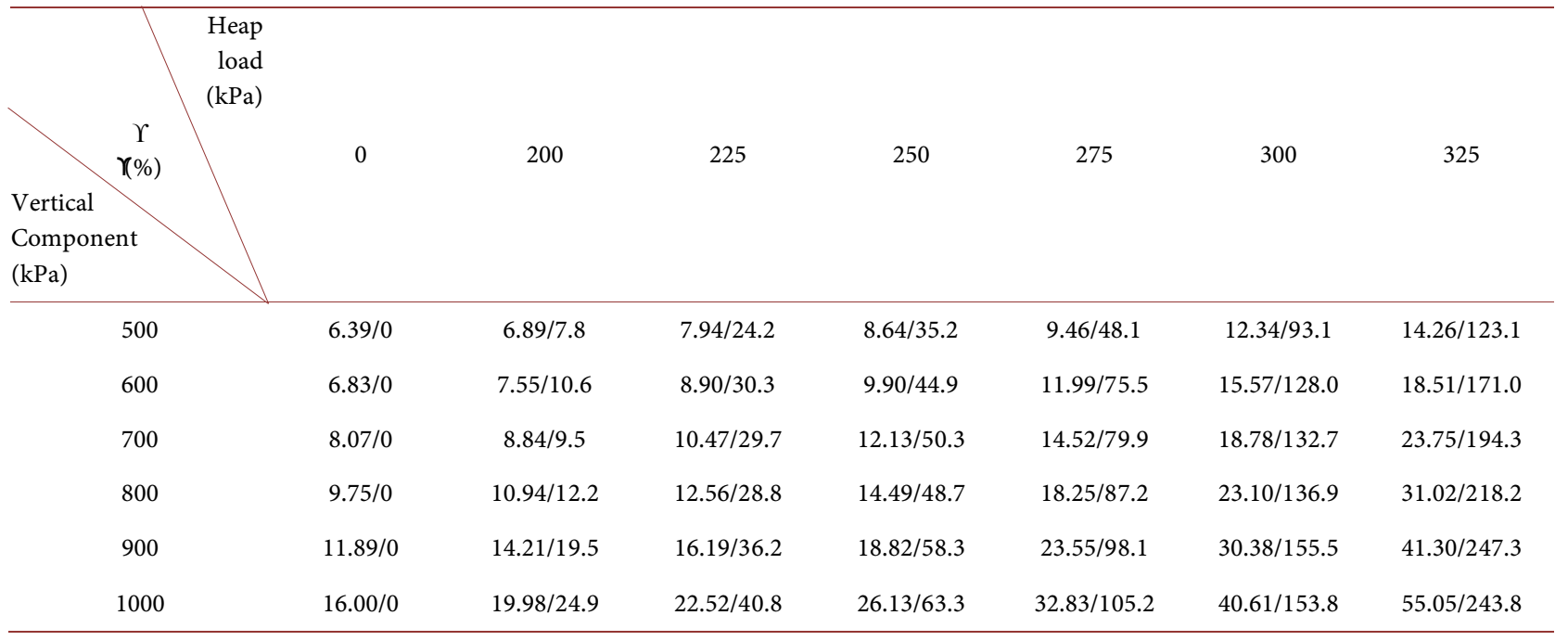

Note: Where $\Upsilon=\frac{D_{N}-D_{0}}{D_{0}}, \Upsilon$ is the degree of influence of pile loading on the displacement of the pile top. $D_{N}$ is the pile top displacement when the load is $N, D_{0}$ is the pile top displacement when the load is 0 .

the heap load is $300 \mathrm{kPa}$, the horizontal displacement under the inclined load is $18.78 \mathrm{~mm}$, the horizontal displacement under horizontal load is $13.98 \mathrm{~mm}$, increasing by $34.3 \%$, this is due to the existence of the vertical load increases load horizontal component of the effect of pile foundation, increase the horizontal displacement, has obvious p- $\Delta$ effect (that is, the second-order gravity effect, buildings with soft lateral stiffness, will produce a large horizontal displacement $\Delta$ under the action of wind load or horizontal earthquake. Due to the vertical load $\mathrm{P}$, the structure will further increase the lateral displacement value. It also causes additional internal forces to be generated by various components inside the structure. This kind of effect that makes the structure geometrically nonlinear is called the second order effect of gravity). Therefore, when the design should fully consider $\mathrm{p}-\Delta$ effect on the deterioration of the horizontal displacement.

Under the combination of heap load and inclined load, the section bending moment of pile is shown in Figure 12.

It can be seen that the distribution law of bending moment of pile under inclined load is similar to that under horizontal load; however, the bending moment of pile under inclined load is slightly greater than that under horizontal load. This is also because the vertical load will increase the pile bending moment.

\section{Conclusions}

1) The vertical displacement of pile is little affected by pile load on the top of slope, the maximum influence degree is $3.5 \%$, and it's almost negligible; however, there is an optimal heap load value that minimizes the vertical displacement. The pile load has a great influence on the horizontal displacement of pile top, the 


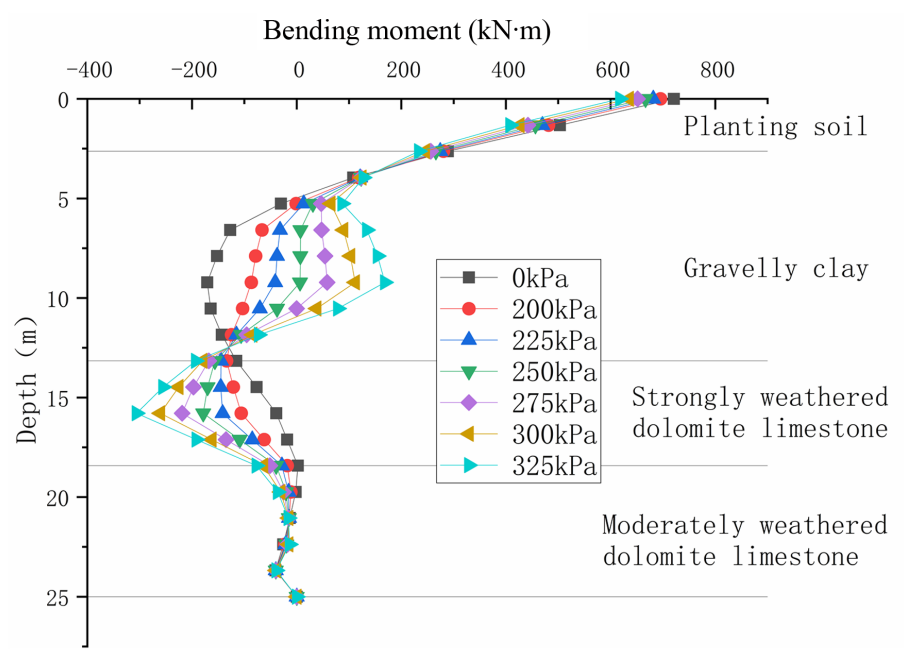

Figure 12. Pile bending moment.

maximum influence degree is up to $100 \%-1271.6 \%$, and there is a threshold of $200 \mathrm{kPa}$; when the pile load on the top of the slope exceeds this threshold, the horizontal displacement on the top of the pile will increase rapidly. Therefore, the actual engineering should avoid the heap load exceeding this value.

2) The bending moment of double pile structure is different from that of single pile structure, the bending moment of double pile foundation is positive at the top and negative at the bottom, the zero bending moment point will descend along the pile with the increase of pile load, and with the increase of heap load on the top of the slope, the pile bending moment will increase gradually.

3) Slope on the bridge pile foundation has obvious p- $\Delta$ effect; the vertical load will aggravate the horizontal displacement under the horizontal load, so in high and steep slope under complicated environment, the design should fully consider the effect of $\mathrm{p}-\Delta$ role.

\section{Conflicts of Interest}

The author declares no conflicts of interest regarding the publication of this paper.

\section{References}

[1] Zhao, M., Zhang, Y., Zhang, Y. and Yin, P. (2013) Bearing Characteristics of Pile Foundation under the Combined Action of Inclined Load and Negative Friction. Journal of Central South University (Natural Science Edition), 44, 757-763.

[2] Feng, Z., Li, X., Su, H., Wang, F., Wang, X., Jian, X., Xu, W. and Ye, F. (2018) Vertical Bearing Characteristics of Bridge Pile Foundation in Deep and Soft Base Area. Road Construction Machinery and Construction Mechanization, 35, 53-59.

[3] Zheng, G., Yu, X., Du, J., Yin, X., Zhou, H. and Yang, X. (2018) Numerical Analysis of Ultimate Bearing Capacity of Strip Foundation near Slope. Rock and Soil Mechanics, 39, 3812-3820+3829.

[4] Wit, E. and McClure, J. (2004) Statistics for Microarrays: Design, Analysis, and In- 
ference. 5th Edition, John Wiley \& Sons Ltd., Chichester.

[5] Chu, C., Dong, M., Hu, Q. and Hou, C. (2015) Study on the Mechanical Characteristics of Bridge Foundation Piles in the Slope of Ship Lock Foundation Pit. Engineering Mechanics, 32, 57-63.

[6] Zhao, M., Chen, Y., Yang, C. and Xiao, Y. (2018) Nonlinear Analysis of Steep Slope Foundation Piles Based on Finite Rod Element Method. Rock and Soil Mechanics, 39, 3020-3028.

[7] Zhao, M., Yang, C., Chen, Y. and Yin, P. (2018) Field Test Research on Double-Pile Foundation of Pile-Column Bridges with High and Steep Slopes. Chinese Journal of Geotechnical Engineering, 40, 329-335. 